\title{
Speed reduction effects over distance of animal-vehicle collision countermeasures - a driving simulator study
}

\author{
Annika K. Jägerbrand ${ }^{1,2,6^{*}}$, Hans Antonson ${ }^{1,3,4}$ and Christer Ahlström ${ }^{1,5}$ (B)
}

\begin{abstract}
Purpose: This study examined if speed reduction effects from animal-vehicle collision (AVC) countermeasures are merely local or do extend to a wider area, and what implications the results have on road planning practice regarding AVCs.

Methods: Twenty-five drivers drove repeatedly on a 9-km long road stretch in a high-fidelity driving simulator. The development of vehicle speed in the surrounding of an automatic speed camera, a wildlife warning sign and a radio message, were investigated in a full factorial within-subject experiment. The factors wildlife fence (with/without) and forest (dense/open landscape) were also included.

Results: The radio warning message had the largest influence on vehicle speed with a speed reduction of $8 \mathrm{~km} / \mathrm{h}$ that lasted beyond $1 \mathrm{~km}$ and $2 \mathrm{~km}$ after the implementation. Eighty-eight per cent of the drivers reported being made extra aware of AVC due to the radio message, which was also associated with stress, insecurity and unsafety. The warning sign reduced vehicle speed by $1.5 \mathrm{~km} / \mathrm{h}$, but speed reductions were not significantly reduced $1 \mathrm{~km}$ after the implementation. Only $8 \%$ of the drivers felt insecure/unsafe after passing the wildlife warning sign, explaining its limited impact on speed. There were no main effects of the automatic speed camera on vehicle speed at longer distances after implementation.

Conclusions: We recommend that AVC countermeasures should be of various design, occur at various segments along the road, and preferably be adaptive and geo-localized to minimize habituation effects on drivers.
\end{abstract}

Key-words: Traffic safety, Accidents, Countermeasures, Mitigation measures, AVC, Planning

\section{Introduction}

Animal-vehicle collisions (AVCs) are a major traffic safety concern since they result in substantial economic and medical costs when causing property damages and injuring or killing humans and animals. Many countries report on a growing number of ungulate-vehicle accidents [1-9] and globally, millions of AVCs occur every year [10-12]. Different types of countermeasures, such as fencing, has proved to be economically attractive and Huijser et al. [13] write that "the benefits through reducing collisions with capybara exceed the costs associated with the mitigation measures".

\footnotetext{
* Correspondence: annika.jagerbrand@calluna.se

1'Swedish National Road and Transport Research Institute (VTI), SE-581 95 Linköping, Sweden

${ }^{2}$ Calluna AB, Hästholmsvägen 28, 13130 Nacka, Stockholm, Sweden Full list of author information is available at the end of the article
}

In Sweden, the overall number of AVCs has been increasing continuously over the last $10-15$ years, especially with roe deer [14] and wild boar [15, 16]. In 2016, the number of animal-vehicle accidents in Sweden reached all-time-high and increased by $21 \%$ compared to the previous year, in numbers increasing from 48,006 to 58,068 AVCs per year [17].

Currently, in the planning practice, the most common countermeasures applied to reduce AVCs are wildlife fencing in combination with wildlife passages and jump-outs. Furthermore, static wildlife warning signs are often implemented in the operation and maintenance phase. Fences are generally considered to reduce AVCs with $75-80 \%$ [18-20], but animals sometimes manage to enter the road area despite fencing [21], and the effectiveness may also depend on the length of the road section [22]. Furthermore, when gaps are present in the 
wildlife fence, e.g. at access roads, wildlife guards (similar to cattle guards) have been proven successful in preventing wildlife from entering the fenced road [23].

Driving behaviour prior to an AVC has rarely been examined [24], despite continually being identified as a crucial factor influencing the probability of AVCs [2529]. Dense forests along the road cause a speed-reducing effect since it is experienced as stressful $[30,31]$ while wildlife fences cause drivers to feel more safe and underestimate AVC risks, leading to increased speeds [24, 31]. Much research has been devoted to how people react to their surroundings and to surrounding features in the landscape [30, 32, 33]. Often the viewer is standing still while the features are fixed, e.g. buildings, trees and signposts. However, when the viewer is on the move, e.g. while driving, the cognitive demand becomes more complex [34]. Apart from a few studies (e.g. [31, 24]) there is still a lack of knowledge concerning how drivers react to wildlife countermeasures such as radio messages, warning sign posts and automatic speed cameras.

Reducing vehicle speed may also be applied as a countermeasure for AVCs since it has been identified as the most effective way of reducing moose collisions for any given traffic volume [35]. Reduced speed is generally an important factor for improved traffic safety [36-38] and has also been identified as a factor affecting the number of AVCs as well as their outcome in terms of human injury severity $[8,35]$.

Implementation of warning signs (e.g., enhanced caution signs, temporary signs, dynamic or variable message signs (VMS) and animal-activated warning signs) may induce speed reductions [39-44], but such studies have mainly been performed under experimentally uncontrolled circumstances. When wildlife warning signs were applied under controlled conditions (i.e. in driving simulations), conventional signs and VMS reduced speed after $300 \mathrm{~m}$ but standard deer warning signs did not [45]. However, in a driving simulator experiment implementing the European standardised triangular animal warning sign (used by countries that have ratified the Vienna Convention on Road Signs and Signals (UN, 1968), it was showed that the sign caused speed reductions both when encountering the sign (200-0 m) and 300-500 m afterwards [24]. Yet, at a distance of 300-500 m, the wildlife warning sign did have a slightly less speed reducing effect than an in-vehicle radio warning message and the velocity profiles revealed that the effects between treatments differed. The long-term effectiveness of warning signs has been questioned since drivers seems to habituate over time [46]. To the best of our knowledge, it has not yet been investigated in controlled conditions how long along the road stretch that AVC countermeasures will continue to cause a speed-reducing effect, even though most AVCs probably do not occur near the implemented AVC countermeasures.

Consequently, there is still a lack of knowledge regarding how different types of AVC countermeasures affect driving speed, and how this knowledge can serve as a better basis for road authorities in their decision-making and planning practice. The main objective of this study was therefore to examine the extension of possible speed reduction effects of automatic speed cameras, radio warning messages and wildlife warning signs, up to $2 \mathrm{~km}$ beyond the countermeasures, and also whether the vehicle speed is affected by the presence of wildlife fences and landscape characteristics (dense forest/open landscapes). More specifically, the following three research questions were investigated: (1) Does speed reduction effects of AVC countermeasures, if any, extend to a wider area? (2) What is the drivers perceived view on the studied AVC countermeasures? (3) What implication does the results have on road planning practice?

To answer these questions, we used data from an experiment conducted in a high-fidelity driving simulator. We have previously published results based on this experiment, focusing on investigating different AVC-relevant landscape settings (vegetation cover), with and without game fencing and in combination with encountering moose, and driving behaviour (speed responses) to various countermeasures at relatively short distances (i.e. $500-300 \mathrm{~m}$ before, $200-0 \mathrm{~m}$ during and 300-500 $\mathrm{m}$ after) from the location where the countermeasures were implemented [24, 31]. Here, however, we present data from longer driving distances up to $2 \mathrm{~km}$ after the implemented countermeasures, a speed camera, a wildlife warning sign and a radio warning message, and include the drivers view on the countermeasures and, moreover, also discuss the implications for road planning practice.

\section{Materials and methods \\ 2.1 Participants}

The official recruitment form issued by the Swedish Road and Transport Research Institute (VTI) was used to recruit 25 participants (10 men and 15 women). The participants were chosen to be reasonably homogeneous in terms of age, gender and driving experience (mean age $40 \pm 6.4$ S.D. year; average $\mathrm{km} /$ year in driving 15,000 $\pm 18,600$ S.D., and had held a driving licence for in average $18.4 \pm 6.5$ S.D. years). Normal ageing has several implications for driving due to cognitive changes and we therefore reduced variation due to age by selecting participants within the range $30-50$ years old. In simulator studies investigating driver reactions and perceptions it is important to include experienced drivers to as far as possible exclude confusion originating from a lack of driving experience. Due to simulator sickness (e.g. [47]), 
Three participants were replaced in an extra simulation session, resulting in a less homogenous sample concerning gender. Only fully completed driving sessions were used in this study.

\subsection{Driving simulator}

Driving simulator III, a high-fidelity moving-base driving simulator located at VTI, Linköping, Sweden, was used in the study (Fig. 1). Vehicle dynamics are simulated with four degrees of freedom by moving, rotating or tilting the simulator containing the car body (Saab 9-3), the projectors and the projection screen. The driving simulator has a vibration table that enables high-fidelity simulation of the road surface. The visual system consists of three DLP projectors, giving the driver a 120 degrees field of vision. Three LCD displays are used to simulate the mirrors.

\subsection{Design and procedure}

The study was carried out in January - February 2011. Participants were informed about the study, about their role, about the extent and duration of the experiment,

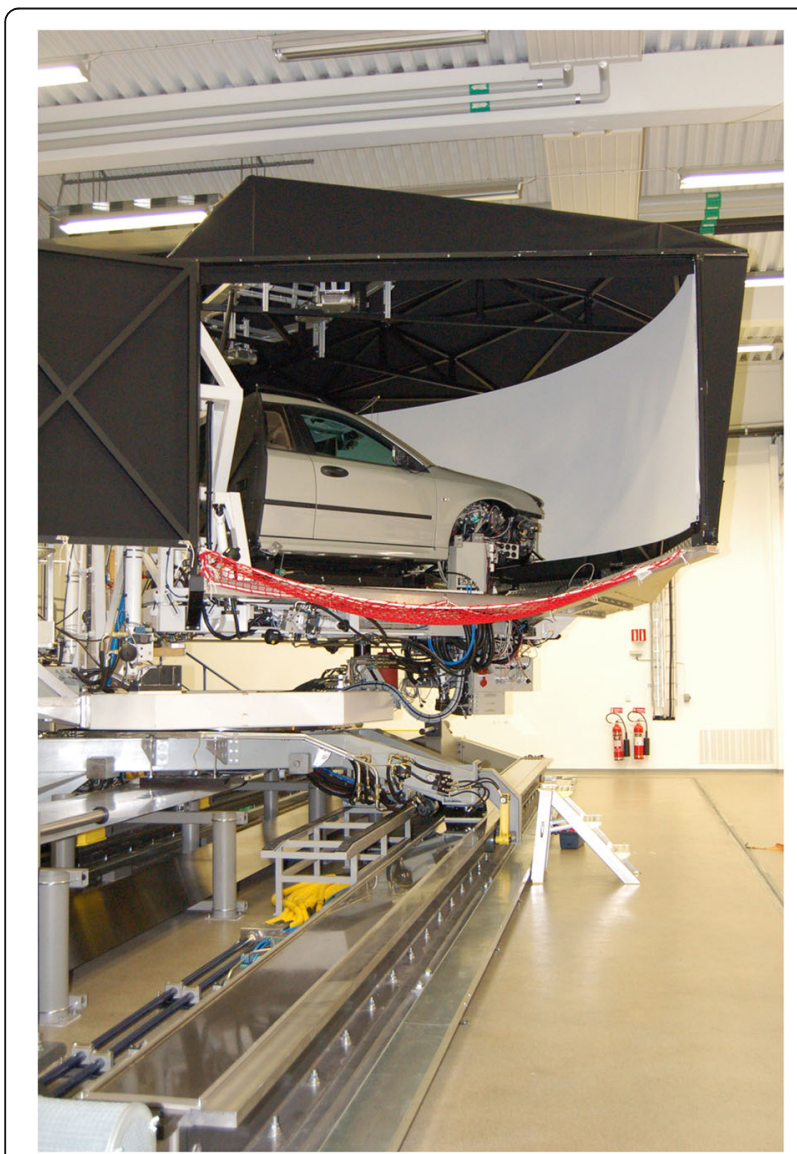

Fig. 1 VTI driving simulator III. The right-hand side of the projector dome is open and the car body (a SAAB 9-3) can be seen inside with the large video screen in front and about driving simulator procedures. They signed an informed consent form and were subsequently thereafter introduced to the driving simulator. The driving session started with a test-drive on a neutral $14.5 \mathrm{~km}$ road to make participants accustomed with the driving conditions and to ensure they did not develop motion sickness. The test-drive road was level and straight and did not include vehicles, signposts, or buildings.

The simulated experimental roads topography and curvature was based on road 621, situated south-west of Linköping, Sweden, and had a speed limit of $90 \mathrm{~km} / \mathrm{h}$. The landscape and factorial settings were designed after a field study along road 34/23 south of Linköping and is described more thoroughly in previously published papers $[24,31]$. The landscapes were draped with a slight mist to simulate natural conditions where ungulates are most active and to reduce visibility and thereby better control when drivers were able to detect measures or factorial variables.

The driving session consisted of eight road stretches, each $9 \mathrm{~km}$ in length, separated by a $1-\mathrm{km}$ neutral road stretch. The driving experiment had a full factorial design, combining all independent, fixed factors in all combinations possible. A total of 64 different driving scenarios were tested in the driving simulator. The combinations were allocated in a systematic way to each driving session but organised so that road stretches with moose did not occur twice in a row. The independent fixed factors were: "E24" sign with accompanying automatic speed camera (present/absent), radio message (on/ off), wildlife warning sign (present/absent), and moose (present/absent). Forest (dense forest or open landscape) and wildlife fence (present/absent) were also included as they were considered likely to influence driving behaviour in combination with the other factors. The fixed factors were placed at specific locations along the road stretch (Fig. 2).

The automatic speed camera (Fig. 3a) is a common traffic enforcement measure for speed control in Sweden and are obliged by law to be used in combination with an E24 sign to inform drivers that personal data might be collected if they violate the speed limit. In addition, a speed limit sign $(90 \mathrm{~km} / \mathrm{h})$ was situated before the automatic speed camera.

The radio message was played to inform drivers about moose in the vicinity: "Traffic announcement aimed at motorists on Highway 34 between Linköping and Vimmerby at Törnevik: we have received several calls about a moose on the road side of the wildlife fence". The message was played simultaneously as displaying a sign showing the name of the village Törnevik. The radio was only active when playing the moose warning radio message.

The animal warning sign, showing a moose, was located $5500 \mathrm{~m}$ into the road stretch Fig. 3b). A moose 


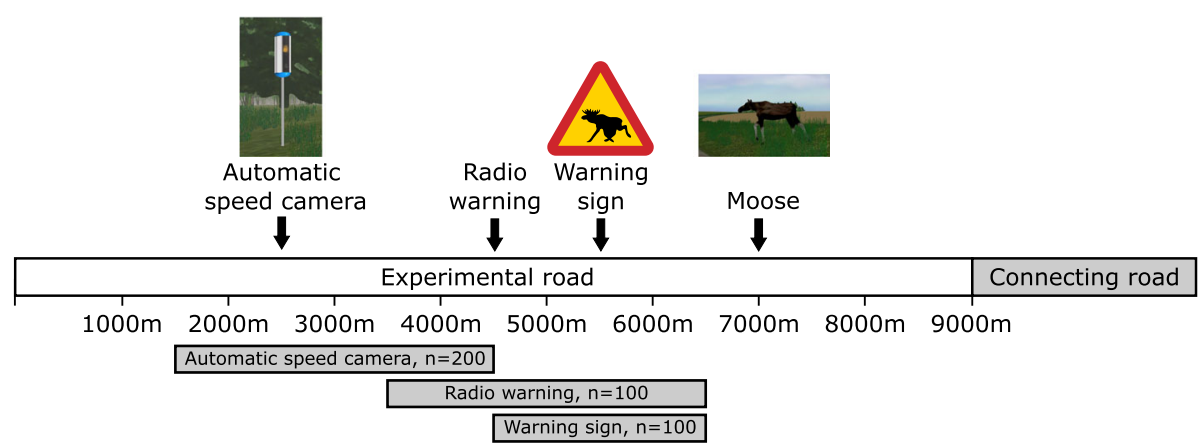

Fig. 2 Road layout for stretches used in the study. The automatic speed camera was located at $2500 \mathrm{~m}$. It was preceded by an "E24" sign at $2200 \mathrm{~m}$ that informs drivers about the upcoming speed camera. The radio warning was presented at $4500 \mathrm{~m}$, a wildlife warning sign (moose) at $5500 \mathrm{~m}$, and the moose was located at $7000 \mathrm{~m}$ after the start. The road stretches also included the variables wildlife fence/no wildlife fence and dense forest or open landscape, not shown here (see Fig. 3). Note that the variables were included in a factorial manner for each road stretch (not all at once). The range of the data surrounding each event, and the number of cases included in the analyses, are illustrated at the bottom
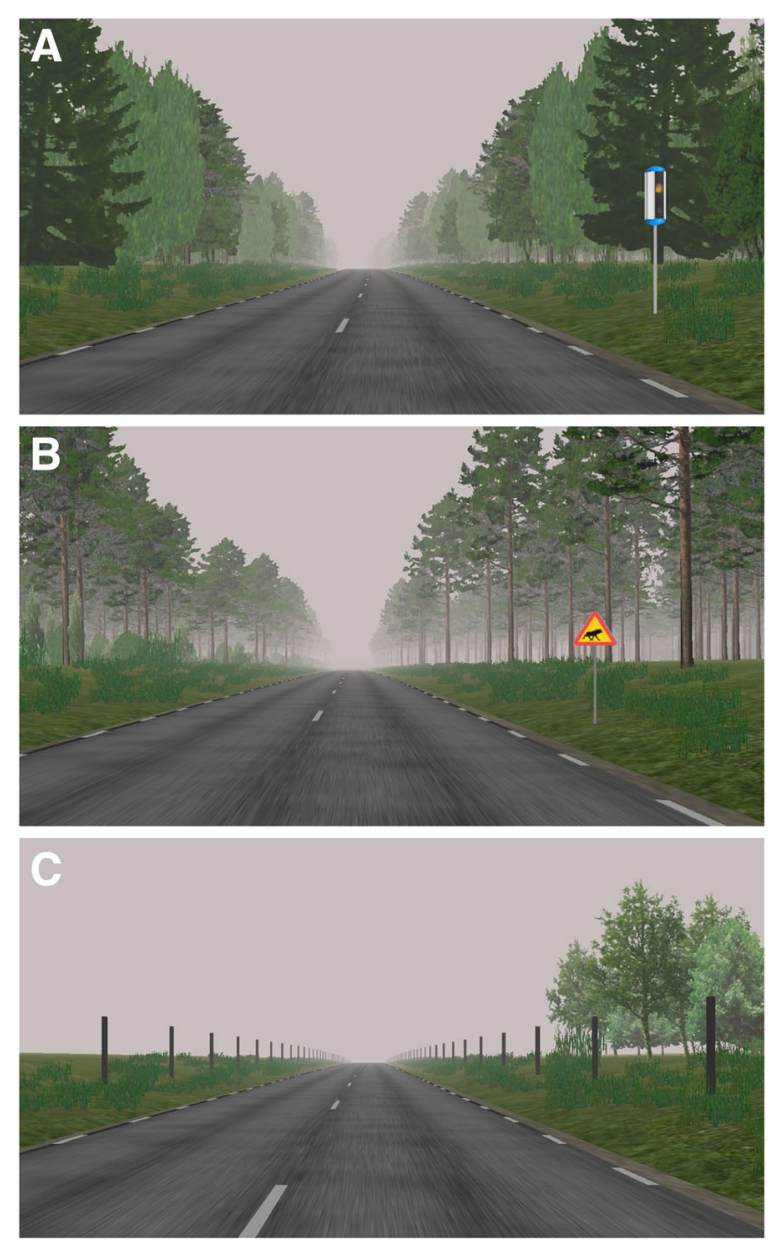

Fig. 3 Examples of the computer animated projections from driving simulator sessions. A) Automatic speed camera and dense forest, B) wildlife warning sign and dense forest, and C) wildlife fence and open landscape decoy was deployed $7000 \mathrm{~m}$ into the road stretch which consisted of a static photograph pasted into the computer animation. The moose encounter is not part of this study, and results are reported elsewhere [24].

The landscape pattern consisted of dense forest (adjacent to the roadside edge) or open landscape consisting of clear cuts, young forest and open fields occasionally interrupted by shrubbery or small patches of forest (Fig. 3 ). The wildlife fence consisted of fixed-knot fencing and treated wooden poles (Fig. 3c).

All driving was executed in right-hand traffic and the speed limit throughout the drive was set to $90 \mathrm{~km} / \mathrm{h}$. Participants were requested to drive as they normally would in comparable conditions. The simulated scenario had low traffic density to ensure that drivers were not distracted by surrounding traffic.

\subsection{Measurements and data processing}

The mean speed was extracted every $5 \mathrm{~m}$ surrounding each event. An 'event' was the occurrence or non-occurrence of an automatic speed camera, radio message, or wildlife warning sign. The range of the data covered a stretch from $1000 \mathrm{~m}$ before the event until $2000 \mathrm{~m}$ after the event $(1000 \mathrm{~m}$ after the event in the case of the warning sign), see Fig. 2. The shorter segment length for the warning sign is due to the presence of the moose decoy, which will greatly influence driving speed [24].

For the automatic speed camera event, the dataset consisted of 200 cases ( 25 drivers $\times 8$ road stretches), and for the radio warning and the warning sign, the data set consisted of 100 cases. Since both the radio message and the warning sign affect driving speed, it was not possible to include road stretches where both factors were active at the same time. This explains the lower number of cases or these factors; road stretches where 
the radio warning was active were excluded from the warning sign analyses and vice versa.

\subsection{Questionnaire data}

The objective simulator data was used in tandem with subjective experiences captured via a questionnaire, which was filled in immediately after the simulator trial. The reason for using a mixed method approach is that the two data sources are complementary, thus providing an increased understanding of the simulator-based results $[48,49]$. As such, the subjective experiences should not be seen as a representative questionnaire study (due to the small sample), but rather as a self-estimation of individual experiences from the simulator trials. The written questionnaire comprised multiple-choice questions. Five questions providing background information about the participants (such as age and gender), 12 questions related to the driving simulator (such as how the participants experienced motion sensation and the road in regard to ease/stress), 2 questions about the participant's living conditions (such as where they grew up and their current home), and 19 questions about the participants' experience of road surroundings during routine driving, whether they were used to driving in the countryside, how the surrounding landscape affected their driving style, and how various features of the surrounding environment affected their everyday driving patterns. The participants had the possibility to add comments as free-text responses. Examples of questions asked were "Does it happen that you are aware of possible game accidents while driving a car? (Yes/No)". "If yes, what makes you aware?" (multiple choices).

\subsection{Statistical analyses}

The full factorial experimental design with 64 different combinations for the driving stretches led to unbalanced replications and a high probability of within-subject dependence, since participants showed large variations in driving behaviour. Moreover, it seemed likely that there could be interdependencies between fixed factors due to the repetition of stretches that included some of the same factors. We therefore decided to investigate the underlying structure of the dependencies in the data and to understand and explore the significance of the AVC countermeasure (i.e. automatic speed camera, radio and warning sign) and other factors (i.e. participant 1-25, wildlife fence and forest) on speed behaviour by multivariate adaptive regression splines (MARS) [50]. MARS is a non-parametric regression technique that can incorporate correlated variables, and automatically models nonlinearities and interactions between factors. MARS was performed using $\mathrm{R}$ version 3.3.2 [51] and the package Earth [52].
The mean speed time series were used as the dependent variable. A dummy variable "measure point" was included to mark the location of the AVC countermeasure along the driven distance, using zeros before the location of the countermeasure and ones after the countermeasure. The independent variables were participants, wildlife fence (present/absent), forest/open landscape, distance and measure point. For each AVC countermeasure and driving stretch, two sets of MARS models were derived, one that included interactions, and the other as an additive model without interactions. This was implemented by using the function "degree" for the forward pass and the maximum degree of interactions (degree $=1$; build an additive model, and degree $=2$; use a model with first order interactions of the hinge functions). Except for the above-mentioned settings, MARS was run in default settings. In total, 6 MARS analyses were performed since the dataset was divided into countermeasure groups. We knew that there existed interactions between AVC countermeasures and the other independent variables $[24,31]$ but we did not know if these interactions were of significance in these specific driving stretches.

MARS analyses showing the best model fit based on lowest generalized cross validation of the model (GCV), highest $\mathrm{R}^{2}$, and higher amount of selected terms and selected predictors were chosen for exhibit coefficients of significance.

As a complement to the MARS analyses, we wanted to analyse if the implementation of the AVC countermeasures would affect vehicle speed at specific distances, and we wanted to include participants as a random factor when testing the effects since participants have a strong influence on the responses. We therefore extracted the mean values of vehicle speed at 800$1000 \mathrm{~m}$ and 1800-2000 $\mathrm{m}$ distance after the location of the three countermeasures. The data were checked for distribution patterns to ensure there was no heterogeneity or overdispersion. Linear regression models were used to test for fixed factors and their interactions and linear mixed-effects models (LME) to include participants (within-subjects) as a random factor. The AVC countermeasures were included as dummy variables. We did not include the order of driving stretches since the previous implemented AVC countermeasures were situated at longer driving distances than $2 \mathrm{~km}$, and also because we have previously shown that the order of the driving stretches is not important [24].

We constructed the two following fixed factors effects model groups: (I) Response variable $\sim$ automatic speed camera + wildlife warning sign + radio warning + forest + fence; and (II) Response variable automatic speed camera + wildlife warning sign + radio warning + forest + fence + two-way interactions 
(between all factors). We tested each of the two models on the two datasets $(800-1000 \mathrm{~m}$ and $1800-$ $2000 \mathrm{~m}$ ) with linear regression. Participants (within-subjects) were added as a random factor in LME-models executed on the groups I and II. We then compared the different models using Akaike's Information Criterion (AIC) to select the model for each dataset that had the highest quality. ANOVA was used to test for significance differences between models, for fixed factor models (group I and II without the random factor) and the fit for the LME models by maximum likelihood (LM) estimates. For both datasets, group II (all variables and their two-way interactions) and the LME model with participants as a random factor had the lowest AIC score. The LME model presented is based on restricted maximum likelihood (REML). Analyses were performed using $\mathrm{R}$ version 3.4.4 and the package nlme [53].

\section{Results}

Main results from MARS analyses show that for all three countermeasures, models with interactions were preferable (Table 1).

Furthermore, vehicle speed is dependent on participants driving behaviour, alone and in combination with other independent variables, especially the countermeasures (Table 2). Many of the selected terms in the resulting MARS models were due to the independent variable participant, either in isolation or as interactions with the other independent variables. These individual differences in driving speed were expected and are not discussed further. The numerous terms related to the variable participant have been excluded from Table 2 for clarity.

For the automatic speed camera, the independent variables wildlife fence $(1.1 \mathrm{~km} / \mathrm{h})$, forest $(-2.6 \mathrm{~km} / \mathrm{h})$, and the interaction between the camera and forest $(2.7 \mathrm{~km} /$ h), were selected as influential (Table 2). The speed profile when approaching the automatic speed camera showed that the drivers started to lower their speed about $500 \mathrm{~m}$ before the speed camera when it became visible (Fig. 4). However, speed quickly returned to baseline levels after about $250 \mathrm{~m}$.

The presence of the radio message was selected as influential on vehicle speed, alone $(-8.0 \mathrm{~km} / \mathrm{h})$ and in interaction with two other independent variables (forest $-1.7 \mathrm{~km} / \mathrm{h}$, measure point $-6.8 \mathrm{~km} / \mathrm{h}$ ) and as interaction with the participants (Table 2). The playback of the radio message gave a delayed effect of this countermeasure. After about $300 \mathrm{~m}$, speed was markedly reduced and the effect lasted for the entire data segment duration. In Fig. 4, the extent of the data segment has been extended for the radio message. However, data extending beyond $2000 \mathrm{~m}$ are confounded by the potential moose encounter and are only used for illustratory purposes.

The presence of the warning sign influenced vehicle speed $(-1.5 \mathrm{~km} / \mathrm{h})$, and so did the measure point ($0.9 \mathrm{~km} / \mathrm{h}$ ) and the wildlife fence $(-29.7 \mathrm{~km} / \mathrm{h}$ ) (Table 2). Also, there was an interaction effect between the warning sign and the wildlife fence $(2.5 \mathrm{~km} / \mathrm{h})$. The slight speed reduction due to the warning sign is discernible in Fig. 4, where the red line is slightly below the blue line after the sign, but the effect is not very clear. The warning sign and its location, along with large interindividual variations, dominates the resulting MARS model. However, the large speed reduction due to the wildlife fence is probably a spurious result.

The LME models that included participants as a random factor was chosen for the best quality of fit in accordance with the lowest AIC scores. For the distance $800-1000 \mathrm{~m}(1 \mathrm{~km})$ after the AVC countermeasure the interaction model was significantly different from the non-interaction fixed factor model, whereas at the distance $1800-2000 \mathrm{~m}(2 \mathrm{~km})$ the models with and without the interactions was not significantly different (Table 3 ). At both $1 \mathrm{~km}$ and $2 \mathrm{~km}$ distance after the AVC countermeasures were implemented, the radio warning still had a significant speed reducing effect (Table 4). There were no speed reducing effects of the automatic speed camera or the wildlife warning sign after $1 \mathrm{~km}$ or $2 \mathrm{~km}$ after the measure was implemented (Table 4). The presence of

Table 1 Results of two MARS analyses (with interactions or as an additive model without interactions) on three datasets: automatic speed camera, radio and warning sign

\begin{tabular}{|c|c|c|c|c|c|c|}
\hline \multirow{2}{*}{$\begin{array}{l}\text { Dataset } \\
\text { MARS model }\end{array}$} & \multicolumn{2}{|c|}{ Automatic speed camera } & \multicolumn{2}{|l|}{ Radio } & \multicolumn{2}{|l|}{ Warning sign } \\
\hline & With interactions & Additive model & With interactions & Additive model & With interactions & Additive mode \\
\hline Terms selected & 32 of 32 & 26 of 26 & 37 of 37 & 24 of 24 & 29 of 29 & 25 of 25 \\
\hline Selected predictors & 5 of 605 & 4 of 605 & 4 of 605 & 4 of 605 & 5 of 405 & 4 of 405 \\
\hline GCV & 29.85 & 31 & 36.2 & 44.5 & 24.87 & 25.7 \\
\hline$R^{2}$ & 0.61 & 0.6 & 0.68 & 0.61 & 0.7 & 0.69 \\
\hline
\end{tabular}

Speed data includes distances according to Fig. 2. Dependent variable: vehicle speed. Independent variables: participants, AVC countermeasure (automatic speed camera, radio, and warning sign coded as dummy variables), wildlife fence, forest/open and measure point (when the countermeasure/event was encountered). $\mathrm{GCV}=$ generalized cross validation of the model and summed over all responses. $\mathrm{R}^{2}=\mathrm{R}$-Squared of the model calculated over all responses. Bold typed $\mathrm{GCV}$ shows the lowest values and the chosen MARS model for each dataset 
Table 2 Results of MARS analysis showing effects on vehicle speed of automatic selection of influential independent variables

\begin{tabular}{|c|c|c|c|c|c|}
\hline \multicolumn{2}{|c|}{ Automatic speed camera } & \multicolumn{2}{|l|}{ Radio } & \multicolumn{2}{|l|}{ Warning sign } \\
\hline Variables & Coefficients & Variables & coefficients & Variables & coefficients \\
\hline (Intercept) & 15.0 & (Intercept) & 131.2 & (Intercept) & 127.7 \\
\hline WF & 1.1 & MEAS & -8.0 & MEAS & -1.5 \\
\hline FOR & -2.6 & MEAS and FOR & -1.7 & WF & -29.7 \\
\hline \multirow[t]{2}{*}{ MEAS and FOR } & 2.7 & MEAS and Measure point & -6.8 & Measure point & -0.9 \\
\hline & & & & MEAS and WF & 2.5 \\
\hline
\end{tabular}

$W F=$ wildlife fence, $M E A S=$ countermeasure (automatic speed camera, radio or warning sign), FOR = forest or open, and measure point (where the countermeasure was employed). MARS analysis was performed on three different datasets for each AVC countermeasure (automatic speed camera, radio, warning sign). Speed data includes distances according to Fig. 2. Results related to the factor participant were excluded from the table for clarity

fence when radio warning was implemented caused a larger speed reducing effect than radio warning alone, but also that there is a speed-reducing effect from driving in the forest (Table 4).

In the written statements collected after the drive, most participants (24 out of 25) answered that there was something during the simulated drives that made them slow down. The main reason was the radio message (72\%), followed by the automatic speed camera (48\%), dense vegetation close to the road (44\%), and the warning sign (44\%). On the opposite question, 16 out of 25 participants answered that there was something during the drives that made them drive faster, with the major reasons being an open landscape (44\%), game fence (36\%) and rural fields close to road (24\%). In terms of insecurity and feeling unsafe, $28 \%$ of all participants felt insecure due to the dense vegetation close to the road, $16 \%$ due to the radio message, and $8 \%$ due to the warning sign. On the opposite question, $64 \%$ of the participants felt comfortable and calm in an open landscape, on wide roads (44\%), with wild fences (24\%). Regarding the participants' general experiences relating to traffic and wild animals, all 25 participants reported that they were aware of the AVC risk while driving. The primary reasons for this awareness were factors such as the time of the day $(88 \%)$, poor visibility $(88 \%)$, warning messages on the radio $(88 \%)$, the type of surrounding vegetation (80\%), and signposts relating to wildlife (76\%). Only $32 \%$ reported that information campaigns made them more aware of AVC.

\section{Discussion}

This study started by asking three questions, namely, (1) Does speed reduction effects of AVC countermeasures, if any, extend to a wider area? (2) What is the drivers perceived view on the studied AVC countermeasures? (3) What implication does the results have on road planning practice?

In relation to the first question we could see that, the AVC countermeasure that had largest influence on vehicle speed over longer distances was the radio warning message, with a speed reduction of about $8 \mathrm{~km} / \mathrm{h}$ that lasted beyond $2 \mathrm{~km}$. Directed warnings, as the radio message, have large impact on behaviour since its scope is limited in both space and time and hence more accurate and relevant to the driver. These findings are in line
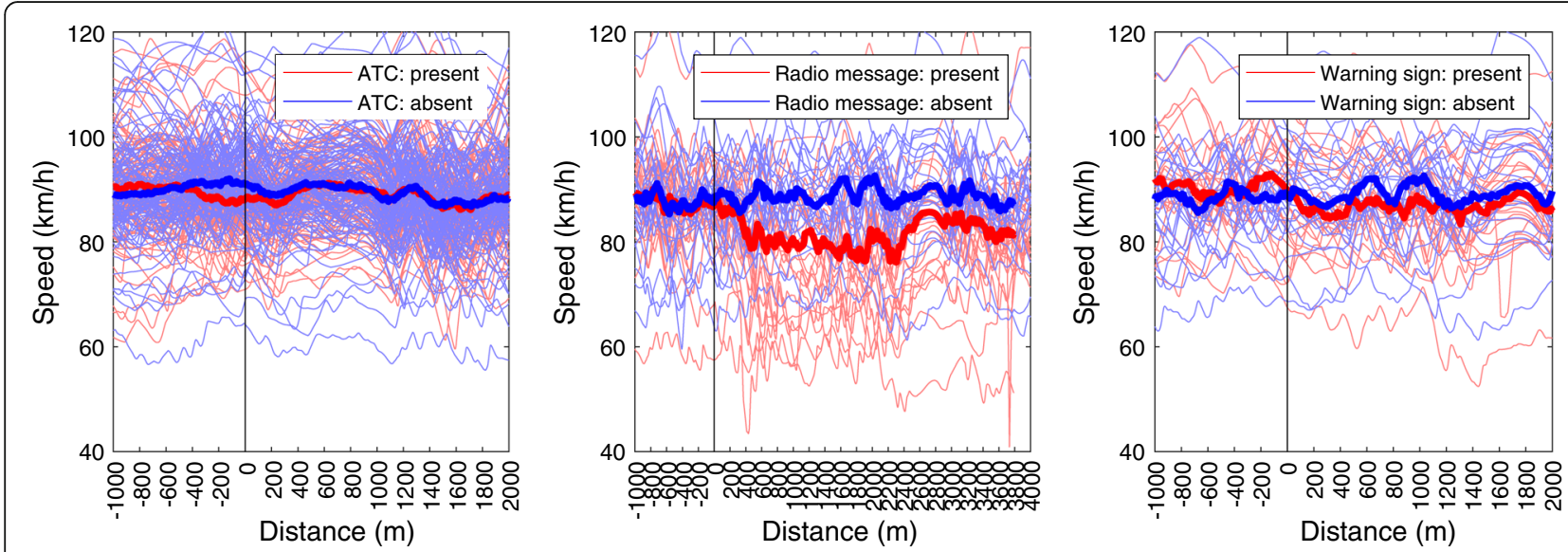

Fig. 4 Speed profiles calculated every $5 \mathrm{~m}$ from $1000 \mathrm{~m}$ before an event until $2000 \mathrm{~m}$ after the event, for all possible road segments according to Fig. 2. Aggregated mean values across all segments are illustrated with thick lines. The extent of the data surrounding the radio message has been extended to $4000 \mathrm{~m}$. Note however that the last $2000 \mathrm{~m}$ are confounded by the potential presence of the moose 
Table 3 Selection of the models based on Akaike's information criterion (AIC) for the two components of random factor effects and fixed factor effects and the linear regression models and the LME models

\begin{tabular}{|c|c|c|c|c|}
\hline \multirow{2}{*}{$\begin{array}{l}\text { Fixed factor group } \\
\text { Random factors }\end{array}$} & \multicolumn{2}{|l|}{ I } & \multicolumn{2}{|l|}{$\|$} \\
\hline & without WS & WS & without WS & WS \\
\hline \multicolumn{5}{|l|}{$\begin{array}{l}\text { Akaike's Information } \\
\text { Criterion (AlC) }\end{array}$} \\
\hline \multicolumn{5}{|l|}{ Response variable } \\
\hline $\begin{array}{l}\text { Velocity } 800-1000 \mathrm{~m} \\
\text { after measure }\end{array}$ & 2171 & 1923 & 2173 & 1900 \\
\hline $\mathrm{ML}^{\mathrm{a}}$ & & 1933 & & 1930 \\
\hline $\begin{array}{l}\text { Velocity 1800-2000 m } \\
\text { after measure }\end{array}$ & 2156 & 1926 & 2160 & 1909 \\
\hline ML (n.s.) & & 1936 & & 1939 \\
\hline
\end{tabular}

Fixed factor groups: $(I)$ response variable (speed) $\sim$ automatic speed camera + wildlife warning sign + radio warning + forest + fence; (II) response variable (speed) $\sim$ automatic speed camera + wildlife warning sign + radio warning + forest + fence + interactions (between all factors)

${ }^{a}=$ The LME model was significantly different at $P<0.05$. n.s. = not significant. $\mathrm{ML}=\mathrm{LME}$ model based on maximum likelihood estimates. Bold typed AICs shows the final model reported in Table 4

with Stanley et al. [45], who found that a variable message sign had a significant speed-reducing effect of $7.4 \mathrm{~km} / \mathrm{h}$. As for the second question, the questionnaire results provided an additional explanation to the longlasting effect of the speed reduction. Eighty-eight per cent of the drivers said that they were made extra aware of AVC due to the radio message. Also, the radio message was associated with stress, insecurity and unsafety, probably since the radio message invoked feelings of a probable imminent and hazardous event.

The long-term effectiveness of warning signs has been questioned since drivers seems to habituate over time
[46]. The results in this study indicate a similar trend, with only a small effect of the warning sign, resulting in a speed reduction of $1.5 \mathrm{~km} / \mathrm{h}$, but a lack of effect after $1 \mathrm{~km}$ and $2 \mathrm{~km}$ after the sign was implemented. Eight per cent of the drivers felt insecure/unsafe after passing the wildlife warning sign, explaining its limited impact on speed. These results are expected. In general, it is very rare to encounter animals on a road stretch with a warning sign, so even though drivers may pay extra attention to the road sides in these areas, it is unlikely that this behaviour is accompanied by a large speed reduction.

The effect of the automatic speed camera was localised to the position of the camera, resulting in a speed reduction stretching from a few hundred meters before the camera to a few hundred meters after the camera. There was a lack of significant speed reductions after $1 \mathrm{~km}$ and $2 \mathrm{~km}$, which is in agreement with previous research [54]. This behaviour, with a rapid deceleration before the camera, followed by acceleration up to the desired speed, is commonly known as kangaroo driving [54]. Since there is generally no speed reduction upstream and downstream of the camera, the usefulness of automatic speed cameras to counter AVC is limited. Even if the camera is placed wisely, in locations where visibility is low and where wildlife crossings are common, the effect is probably limited since AVCs are more related to driver behaviour and road conditions than to animal movements [28].

The effect of the factors wildlife fence and forest were not studied directly. However, in general, dense forest close to the road reduced the vehicle speed whereas the presence of a wildlife fence increased the speed. These results also agree with the drivers perceived view based on the questionnaire responses, where $44 \%$ of the

Table 4 Results of linear mixed-effects (LME) model explaining response variables in the driving simulator experiment by testing the effects of different animal-vehicle collision countermeasures (radio warning, wildlife warning sign, automatic speed camera) and the presence and absence of wildlife fence and dense forest versus open landscape

\begin{tabular}{|c|c|c|c|c|c|}
\hline Variable & Coefficient & SE & DF & $t$ value & $P$ \\
\hline \multicolumn{6}{|l|}{ Velocity 800-1000 $m$ after measure } \\
\hline Intercept & 90.6241 & 1.638464 & 263 & 55.31041 & $<0.0001$ \\
\hline Radio warning & -5.69822 & 2.251078 & 263 & -2.53133 & 0.0119 \\
\hline Fence & 2.78884 & 1.059812 & 263 & 2.63144 & 0.009 \\
\hline Forest & -2.22164 & 1.034645 & 263 & -2.14725 & 0.0327 \\
\hline Radio warning and fence & -7.57272 & 2.445421 & 263 & -3.0967 & 0.0022 \\
\hline \multicolumn{6}{|l|}{ Velocity 1800-2000 m after measure } \\
\hline (Intercept) & 90.39819 & 1.588899 & 263 & 56.8936 & $<0.0001$ \\
\hline Radio warning & -9.13026 & 2.296188 & 263 & -3.97627 & 0.0001 \\
\hline Forest & -3.52007 & 1.055447 & 263 & -3.33515 & 0.001 \\
\hline Wildlife warning sign and forest & 5.57434 & 2.455735 & 263 & 2.26993 & 0.024 \\
\hline
\end{tabular}

Only significant variables are shown. The model was run separately for each distance (i.e. 800-1000 $\mathrm{m}$ and $1800-2000 \mathrm{~m}$ after the measure was implemented, respectively). Final LME models are shown in Table 3. Significant explanatory variables are shown in bold type $(P<0.05)$. Random effects at $800-1000$ m: standard deviation intercept 7.2, residual 5.1, and at 1800-2000 m: standard deviation intercept 6.9, residual 5.2 
participants reported that they decreased their speed when there was dense forest close to the road, and 36\% reported that the presence of wildlife fences was a reason to increase the vehicle speed. These results agree with previous studies, where dense forests along the road have been found to cause a speed-reducing effect $[30,31]$ and wildlife fences cause drivers to feel more safe and underestimate AVC risks, and therefore drive faster $[24,31,55]$. When the radio warning and fence co-occurred, it caused a larger speed reduction than radio warning per se $1 \mathrm{~km}$ after the radio warning was implemented. This indicates that the drivers are more concerned by the radio message when they imagine a moose being trapped inside the fence. This is probably due to the higher risk of having a wildlife collision under such circumstances.

There are three important AVC countermeasures that we regard as important for the third research question concerning implications on planning practice: the radio message, wildlife fences and the roadside landscape. As discussed above, the radio message works so well because it provides a warning that is localised in time and space, and is thus very relevant to the driver. A practical difficulty is of course that directed warning messages requires accurate and timely information about the presence of animals close to the road. A less direct warning, such as a wildlife warning sign, is obviously easier to implement, but not as effective. To be effective in the planning phase, any implemented AVC countermeasure should be relevant enough for the drivers, by considering time/space localisation and by minimize the drivers' habituation effect. Examples of such AVC countermeasures include mobile and/or variable message warning signs. Different designs can be used to make the warnings more effective in reducing vehicle speed. For example, it is possible to use moose decoys or large wildlife artworks along the road to increase the variation in warning design [24], but such AVC countermeasures are rarely implemented. To minimize the habituation effect, community-based geo-localized AVCs can be collected in an app that can be used while driving. Under such circumstances, it would be possible to receive warnings where many AVCs has taken place. In Sweden, the Swedish Council for the Prevention of Wildlife-Vehicle Accidents (SCPWVA) have developed a mobile app called "Viltolycka", that makes it possible to receive active warnings on where along the route AVCs has occurred in the past. Even if the likelihood that an AVC will take place at the exactly same location is unknown, it is likely that the driver will increase his/her attention for wildlife on the road and decrease speed during longer distances. Hitherto, no studies have yet investigated driver behaviour when using AVC apps. The lasting effect over distance and consistent responses to directed radio messages shown in this study could however be used as an indication of what to expect in terms of AVC apps. When it comes to wildlife fences, there are two planning aspects that need to be considered, price and landscape impact. There are several ways to erect a fence along the road, all with a different impact on the landscape. Where there is forest close to the road, the fence can be erected a few metres beyond the forest edge, making the fence less visible to the naked eye. This approach may be positive in the sense that a less visible fence will avoid the issue with drivers feeling more secure [55]. Hidden fences may also have a touristic implication for visitors viewing the landscape, by not distorting their experiences of the countryside [56]. Such issues should be included in cost-benefit analyses as a decision support tool for transportation agencies, along with the direct benefit of the mitigation measures [13]. In an open landscape, e.g. in rural areas, this approach is obviously less applicable.

When it comes to forested landscapes, Finder et al. [57] found that the distance to forest cover is an important deer-vehicle accident predictor, and Seiler [35] noted that an increased distance of $100 \mathrm{~m}$ between forest cover and road might significantly reduce collisions with moose. Malo et al. [11] noted that animals prefer to approach roads in the proximity of trees and shrubs. Similarly, concerning Sweden, Seiler [35] found that the proximity and amount of forest habitats providing forage and cover significantly affected the risk of moose-vehicle collisions. It may also be beneficial to mow the road sides at strategic times [58, 59], such as early summer [60]. Thus, keeping the road side clear from vegetation and trees do not only increase the sight distance and consequently the likelihood of detecting animals in time, it should also generally reduce forage opportunities and coverage, giving the animals less reason to be close to the road.

Transport agencies, with their limited budgets, needs well substantiated support to be able to get the most out of their investments. For example, erecting wildlife fences effectively reduce the number of AVCs, but it is also extremely expensive, especially since fencing must be combined with fauna passages to ensure connectivity. The Swedish Transport Administration, who is responsible for all national roads in Sweden except for the municipal roads in cities and in the suburbs, currently lack a wildlife policy that can prioritize between different AVC countermeasures. In the road planning phase, a cost-benefit analysis is used to ensure that wildlife fences are erected when costs of AVCs are expected to be high. Recently, however, the Swedish Transport Administration has decided that there must be a possibility for wildlife animals to get across transport structures at least every fourth kilometre on some countryside roads (speed 
limit above $80 \mathrm{~km} / \mathrm{h}$, or equipped with wildlife fences, or with an average of at least 4000 vehicles per year) [61]. The distance is based on mean values of home-range areas/sizes $\left(\mathrm{HR}^{0.5}\right)$ for moose in Sweden, as has been suggested by Bissonette and Adair [62]. However, when considering countermeasures to enhance connectivity in the operation and maintenance of roads, it is considered possible to maximize the distance between crossings up to $6 \mathrm{~km} \mathrm{[63].}$

Unfortunately, there are currently no guidelines proposed by the Swedish Transport Administration about the prerequisites for choosing different types of AVC countermeasures and regarding other policy areas such as e.g., tourism. In anticipation of a wildlife policy being made for roads, the effect of various AVC countermeasures is extremely important to document as we have done here. However, there is a high risk that the results may be used ad hoc and not considered in a broader planning context.

There are some limitations to this study. It was originally intended to measure, for each of the 200 (100) cases in Fig. 2 , when speed had returned to baseline levels. As it turned out, the large individual differences that were highlighted in the MARS analyses and that are also clearly visible in Fig. 4, made this approach impossible. For example, some drivers already drove below the speed limit before the automatic speed camera and a few of these drivers increased their speed when approaching the camera. Another example is that some drivers didn't react at all to the countermeasures, making it difficult to extract a meaningful longitudinal measure. The large intra-individual variations indicate that there is a need to add more participants to the experiment. Unfortunately, this was not possible within the scope of this project. It is also a limitation that the study was run in a simulator and not in a real environment. The main reason for running the experiment in a simulator is that the moose encounter (not reported in this paper) would have been difficult to set up in a field setting. The main disadvantage with this setup is the inherent difficulty in maintaining a steady speed in simulators [64]. All in all, this means that it is necessary to aggregate data from multiple trials and several participants before any trends become visible (the thick lines in Fig. 4). For these reasons, we have decided not to calculate any inferential statistics related to how long the effect of a countermeasure lasts, but instead used the distances of $1 \mathrm{~km}$ and $2 \mathrm{~km}$ to test the effect of the AVC countermeasures after these distances. Since the study was run in a simulator, and since the sample used in the experiment was rather homogenous in terms of age and driving experience, one should be careful when generalising the results to real road driving and to other age and driving experience groups.

\section{Conclusions}

A driving simulator was used to determine the extension of possible effects on driving behavior of three AVC countermeasures: an automatic speed camera, a wildlife warning sign and a radio message. The directed warning, i.e., the radio message, had the largest influence on vehicle speed over longer distance, and seem to last beyond $2 \mathrm{~km}$ while automatic speed camera and wildlife warning sign did not last beyond $1 \mathrm{~km}$ after the implementation. $72 \%$ of the participants answered that they slowed down due to the radio message, whereas only $44 \%$ and $48 \%$ stated that they slowed down because of the wildlife warning sign or the automatic speed camera, respectively. Considering the road planning practice, we recommend that the AVC countermeasures implemented should be of various design (e.g., size and shape), occur at various segments along the road (mobile), and preferably be directed or variable to minimize the habituation effects on drivers. The latter recommendation is our main contribution to the international research on AVCs.

\section{Acknowledgements \\ We are grateful for the financial support by Viltolycksfonden and Älgskadefondsföreningen that made this paper possible. The original study (simulator experiment) was funded by the Swedish Environmental Protection Agency, the Wildlife Management Fund (project number 802-0224-09). They are gratefully acknowledged. Special thanks to Annika and Lars Sävberger, Mats Wiklund, and the staff at VTI for their assistance with the simulator study. We also thank Sveriges Radio for help with the radio message.}

\section{Authors' contributions \\ All authors participated in designing the experimental design and in writing of the manuscript. All authors read and approved the final manuscript.}

\section{Competing interests}

The authors declares that they have no competing interests.

\section{Publisher's Note}

Springer Nature remains neutral with regard to jurisdictional claims in published maps and institutional affiliations.

\section{Author details}

${ }^{1}$ Swedish National Road and Transport Research Institute (VTI), SE-581 95 Linköping, Sweden. ${ }^{2}$ Calluna AB, Hästholmsvägen 28, 13130 Nacka, Stockholm, Sweden. ${ }^{3} \mathrm{KMV}$ forum AB, Hästholmsvägen 28, SE-131 30 Nacka, Stockholm, Sweden. ${ }^{4}$ Department of Human Geography, Lund University, SE-223 62 Lund, Sweden. ${ }^{5}$ Department of Biomedical Engineering, Linköping University, SE-581 83 Linköping, Sweden. ${ }^{6}$ Department of Construction Engineering and Lighting Science, School of Engineering, Jönköping University, P.O. Box 1026, SE-551 11 Jönköping, Sweden.

Received: 9 January 2018 Accepted: 22 August 2018

Published online: 03 September 2018

\section{References}

1. Groot Bruinderink GWTA, Hazebroek E (1996) Ungulate traffic collisions in Europe. Conserv Biol 10(4):1059-1067

2. Putman RJ (1997) Deer and road traffic accidents: options for management. J Environ Manag 51(1):43-57

3. Hothorn T, Brandl R, Müller J (2012) Large-scale model-based assessment of deer-vehicle collision risk. PLoS One 7(2). https://doi.org/10.1371/journal. pone. 0029510

4. Morelle K, Lehaire F, Lejeune P (2013) Spatio-temporal patterns of wild lifevehicle collisions in a region with a high-density road network. Nature Conservation 5:53-73. https://doi.org/10.3897/natureconservation.5.4634 
5. Sullivan JM (2011) Trends and characteristics of animal-vehicle collisions in the United States. J Saf Res 42(1):9-16. https://doi.org/10.1016/j.jsr.2010.11.002

6. Hubbard MW, Danielson BJ, Schmitz RA (2000) Factors influencing the location of deer-vehicle accidents in lowa. J Wildl Manag 64:707-713

7. McKee JJ, Cochran DM Jr (2012) The role of landscape in the distribution of deer-vehicle collisions in South Mississippi. Southeast Geogr 52(3):327-340

8. Langbein J, Putman RJ, Pokorny B (2011) Road traffic accidents involving ungulates and available measures for mitigation. In: Putman RJ, Apollonio M, Andersen R (eds) Ungulate management in Europe: problems and practices. Cambridge University Press, Cambridge, pp 215-259

9. Sáenz-de-Santa-María A, Tellería JL (2015) Wildlife-vehicle collisions in Spain. Eur J Wildl Res 61(3):399-406. https://doi.org/10.1007/s10344-015-0907-7

10. Conover MR, Pitt WC, Kessler KK, Dubow TJ, Sanborn WA (1995) Review of human injuries, illnesses, and economic losses caused by wildlife in the United States. Wildl Soc Bull 23(3):407-414

11. Malo JE, Suarez F, Diez A (2004) Can we mitigate animal-vehicle accidents using predictive models? J Appl Ecol 41(4):701-710

12. Romin LA, Bissonette JA (1996) Deer-vehicle collisions: status of state monitoring activities and mitigation efforts. Wildl Soc Bull 24(2):276-283

13. Huijser MP, Abra FD, Duffield JW (2013) Mammal road mortality and costbenefit analyses of mitigation measures aimed at reducing collisions with capybara (Hydrochoerus hydrochaeris) in São Paulo state, Brazil. Oecologia Australis 17(1):129-146. https://doi.org/10.4257/oeco.2013.1701.11

14. Jägerbrand AK (2014) Collisions and accidents with roe deer in Sweden during 10 years (2003-2012). Variation in time, geographical patterns and costs. Report 818, VTI, the Swedish national road and transport research institute, (in Swedish with English summary)

15. Gren IM, Häggmark-Svensson $T$, Andersson $H$, Jansson $G$, Jägerbrand $A$ (2016) Using traffic data to estimate wildlife populations. J Bioecon 18(1): 17-31. https://doi.org/10.1007/s10818-015-9209-0

16. Häggmark-Svensson T, Gren IM, Andersson H, Jansson G, Jägerbrand AK (2014) Cost of traffic accidents with wild boar populations in Sweden. Working paper series 2014:5, Swedish University of Agricultural Sciences, Department of Economics, https://ideas.repec.org/p/hhs/slueko/2014_005.html

17. NVR (2016) Statistik. The Swedish National Wildlife Accident Council, http:// www.viltolycka.se/statistik/

18. Almkvist B, André T, Ekblom S, Rempler S-A (1980) Viltolycksprojektet (VIOL) Slutrapport maj 1980. TU 146. Statens vägverk, Utvecklingssektionen, 1142, https://www.algen.se/wp-content/uploads/viltolycksprojektet-violslutrapport.pdf (in Swedish)

19. Erke A, Elvik R (2006) Road safety measures: a catalogue of estimated effects. TØ। report 851/2006, Oslo 2006-09. Norwegian Centre for Transport Research, Institute of Transport Economics (TØI) and Stiftelsen Norsk senter for samferdselsforskning, 1-119. https://www.toi.no/getfile.php?mmfileid= 4925 (in Norwegian)

20. Swedish Transport Administration (2016) Bygg om eller bygg nytt - Kapitel 6 Trafiksäkerhet, Version 2016-04-01 (in Swedish)

21. Cserkész T, Ottlecz B, Cserkész-Nagy Á, Farkas J (2013) Interchange as the main factor determining wildlife-vehicle collision hotspots on the fenced highways: spatial analysis and applications. Eur J Wildl Res 59(4):587-597

22. Huijser MP, Fairbank ER, Camel-Means W, Graham J, Watson V, Basting P, Becker D (2016) Effectiveness of short sections of wildlife fencing and crossing structures along highways in reducing wildlife-vehicle collisions and providing safe crossing opportunities for large mammals. Biol Conserv 197:61-68. https://doi.org/10.1016/j.biocon.2016.02.002

23. Allen TDH, Huijser MP, Willey DW (2013) Effectiveness of wildlife guards at access roads. Wildl Soc Bull 37(2):402-408. https://doi.org/10.1002/wsb.253

24. Jägerbrand AK, Antonson H (2016) Driving behaviour responses to a moose encounter, automatic speed camera, wildlife warning sign and radio message determined in a factorial simulator study. Accid Anal Prev 86:229-238. https:// doi.org/10.1016/j.aap.2015.11.004

25. Hedlund JH, Curtis PD, Curtis G, Williams AF (2004) Methods to reduce traffic crashes involving deer: what works and what does not. Traffic Inj Prev 5(2):122-131. https://doi.org/10.1080/15389580490435079

26. Putman RJ, Langbein J, Staines BW (2004) Deer and road traffic accidents: a review of mitigation measures: cost and cost-effectiveness. Report for the Deer Commission for Scotland; contract RP23A, 1-96, https://pdfs. semanticscholar.org/598d/bc9dda0fd9816d485f87589ce0cd3aaa4848.pdf

27. Knapp KK (2005) Crash reduction factors for deer-vehicle crash countermeasures: state of the knowledge and suggested safety research needs. J Transp Res Board 1908: 172-179
28. Neumann W, Ericsson G, Dettki H, Bunnefeld N, Keuler NS, Helmers DP, Radeloff VC (2012) Difference in spatiotemporal patterns of wildlife roadcrossings and wildlife-vehicle collisions. Biol Conserv 145(1):70-78. https:// doi.org/10.1016/j.biocon.2011.10.011

29. Niemi M, Rolandsen CM, Neumann W, Kukko T, Tiilikainen R, Pusenius J, Solberg EJ, Ericsson G (2017) Temporal patterns of moose-vehicle collisions with and without personal injuries. Accid Anal Prev 98:167-173. https://doi. org/10.1016/j.aap.2016.09.024

30. Antonson H, Mårdh S, Wiklund M, Blomqvist G (2009) Effect of surrounding landscape on driving behaviour: a driving simulator study. J Environ Psychol 29(4):493-502

31. Antonson $\mathrm{H}$, Jägerbrand $\mathrm{A}$, Ahlström C (2015) Experiencing moose and landscape while driving: a simulator and questionnaire study. J Environ Psychol 41:91-100. https://doi.org/10.1016/j.jenvp.2014.11.010

32. Antonson H, Ahlström C, Mårdh S, Blomqvist G, Wiklund M (2014) Landscape heritage objects' effect on driving: a combined driving simulator and questionnaire study. Accid Anal Prev 62:168-177 doi:https://doi.org/10. 1016/j.aap.2013.09.021 (Supplement C)

33. Gifford R (2014) Environmental psychology matters. Annu Rev Psychol 65: 541-579

34. Ulrich RS, Simons RF, Losito BD, Fiorito E, Miles MA, Zelson M (1991) Stress recovery during exposure to natural and urban environments. J Environ Psychol 11(3):201-230

35. Seiler A (2005) Predicting locations of moose-vehicle collisions in Sweden. J Appl Ecol 42(2):371-382. https://doi.org/10.1111/j.1365-2664.2005.01013.x

36. Godley ST, Triggs TJ, Fildes BN (2002) Driving simulator validation for speed research. Accid Anal Prev 34(5):589-600. https://doi.org/10.1016/s00014575(01)00056-2

37. Nilsson G (2004) Traffic safety dimensions and the power model to describe the effect of speed on safety. Bulletin 221, Dissertation, Lund Institute of Technology and Society, Lund University, http://lup.lub.lu.se/record/21612

38. Elvik R, Vaa T (2008) The handbook of road safety measures, 1st edn. Emerald Group Publishing Limited, PI Antony Rowe, Chippenham and Eastbourne

39. Hardy A, Lee S, Al-Kaisy AF (2006) Effectiveness of animal advisory messages on dynamic message signs as a speed reduction tool - case study in rural Montana. Transportation Res Record: J Transportation Res Board 1973:64-72

40. Mastro LL, Conover MR, Frey SN (2010) Factors influencing a motorist's ability to detect deer at night. Landsc Urban Plann 94(3-4):250-254. https:// doi.org/10.1016/j.landurbplan.2009.10.010

41. Al-Ghamdi AS, AlGadhi SA (2004) Warning signs as countermeasures to camel-vehicle collisions in Saudi Arabia. Accid Anal Prev 36(5):749-760. https://doi.org/10.1016/j.aap.2003.05.006

42. Grace MK, Smith DJ, Noss RF (2015) Testing alternative designs for a roadside animal detection system using a driving simulator. Nature Conservation 11:61-77. https://doi.org/10.3897/natureconservation.11.4420

43. Sullivan TL, Williams AF, Messmer TA, Hellinga LA, Kyrychenko SY (2004) Effectiveness of temporary warning signs in reducing deer-vehicle collisions during mule deer migrations. Wildl Soc Bull 32(3):907-915. https://doi.org/ 10.2193/0091-7648(2004)032[0907:EOTWSI]2.0.CO;2

44. Found R, Boyce MS (2011) Warning signs mitigate deer-vehicle collisions in an urban area. Wildl Soc Bull 35(3):291-295. https://doi.org/10.1002/wsb.12

45. Stanley L, Hardy A, Lassacher S (2006) Responses to enchanced wildlife advisories in a simulated environment. Transportation Res Record: J Transportation Res Board 1980:126-133

46. Pojar TM, Prosence RA, Reed DF, Woodard TN (1975) Effectiveness of a lighted, animated deer crossing sign. J Wildl Manag 39(1):87-91

47. Mourant RR, Thattacherry TR (2000) Simulator sickness in a virtual environments driving simulator. In: Ergonomics for the New Millennium. The XIVth Triennial Congress of the International Ergonomics Association and 44th Annual Meeting of the Human Factors and Ergonomics Association, San Diego, pp 534-537

48. Creswell JW, Creswell JD (2018) Research design: qualitative, quantitative, and mixed methods approaches. 5th rev ed, Sage publications, Los Angeles

49. Kweon B-S, Ellis CD, Lee S-W, Rogers GO (2006) Large-scale environmental knowledge: investigating the relationship between self-reported and objectively measured physical environments. Environ Behav 38(1):72-91

50. Friedman JH (1991) Multivariate adaptive regression splines. Ann Stat 19(1):1-141

51. R Core Team (2016) R: a language and environment for statistical computing. $R$ Foundation for statistical computing, Vienna URL https:/www.R-project.org/ 
52. Milborrow S (2016) earth: Multivariate Adaptive Regression Splines. R package version 4.4.6. . https://CRAN.R-project.org/package=earth

53. Pinheiro J, Bates D, DebRoy S, Sarkar D, Team RC (2018) NIme: linear and nonlinear mixed effects models. R package version 3:1-137 https:// CRAN.R-project.org $/$ package $=$ nIme

54. Høye A (2014) Speed cameras, section control, and kangaroo jumps-a meta-analysis. Accid Anal Prev 73:200-208

55. Näätänen R, Summala H (1976) Road-user behaviour and traffic accidents. North-Holland publishing company, Amsterdam

56. Jacobsen JKS, Antonson H (2017) Motivational segments for trips along the high coast byway of Sweden: a study of local leisure excursions and domestic holidaymaking. Scand J Hosp Tour 17(2):177-193

57. Finder RA, Roseberry JL, Woolf A (1999) Site and landscape conditions at white-tailed deer/vehicle collision locations in Illinois. Landsc Urban Plann 44(2-3):77-85. https://doi.org/10.1016/S0169-2046(99)00006-7

58. Rea RV (2003) Modifying roadside vegetation management practices to reduce vehicular collisions with moose Alces alces. Wild Biol 9(2):81-91

59. Seiler A, Olsson M (2009) Are non-wildlife underpasses effective passages for wildlife? In: Proceedings from the 2009 International Conference on Ecology \& Transportation, ICOET, Duluth Minnesota, North Carolina State University, 13-17 September 2009, pp 317-331

60. Rea RV, Child KN, Spata DP, MacDonald D (2010) Road and rail side vegetation management implications of habitat use by moose relative to brush cutting season. Environ Manag 46(1):101-109. https://doi.org/10.1007/ s00267-010-9502-6

61. Swedish Transport Administration (2016) Riktlinje landskap, TDOK 2015:0323 (in Swedish)

62. Bissonette JA, Adair W (2008) Restoring habitat permeability to roaded landscapes with isometrically-scaled wildlife crossings. Biol Conserv 141(2): 482-488. https://doi.org/10.1016/j.biocon.2007.10.019

63. Seiler A, Olsson M, Lindqvist M (2015) Analys av infrastrukturens permeabilitet för klövdjur. Rapport från forskningsprogrammet TRIEKOL, Publikationsnummer: 2015:254, Swedish Transport Administration (in Swedish with English summary)

64. Greenberg J, Blommer M (2011) Physical Fidelity of driving simulators. In: Fisher D, Rizzon M, Caird J, Lee J (eds) Handbook of driving simulation for engineering, medicine, and psychology. CRC Press, Boca Raton Fl

\section{Submit your manuscript to a SpringerOpen ${ }^{\circ}$ journal and benefit from:}

- Convenient online submission

- Rigorous peer review

- Open access: articles freely available online

- High visibility within the field

- Retaining the copyright to your article

Submit your next manuscript at $\boldsymbol{\nabla}$ springeropen.com 